\title{
Nephroprotective effect of methanol extract of Moringa oleifera leaves on acute kidney injury induced by ischemia-reperfusion in rats
}

\author{
Akinleye Stephen Akinrinde ${ }^{1}$, Olusegun Oduwole ${ }^{2}$, Fadeyemi Joseph Akinrinmade ${ }^{2}$, \\ Folusho Bolawaye Bolaji-Alabi ${ }^{2}$
}

\begin{abstract}
1. Department of Veterinary Physiology and Biochemistry, Faculty of Veterinary Medicine, University of Ibadan, Nigeria.

2. Department of Veterinary Surgery and Radiology, Faculty of Veterinary Medicine, University of Ibadan, Nigeria.
\end{abstract}

\begin{abstract} rat model of renal ischemia-reperfusion (IR) injury. erfusion up to 24 hours. ation of tissue oxidative stress.

DOI: https://dx.doi.org/10.4314/ahs.v20i3.44 ahs.v20i3.44

\section{Introduction}

Acute kidney injury due to renal ischemia and reperfusion contributes to high morbidity, delayed graft function, graft rejection and mortality in the post-operative period following procedures such as kidney transplantation. ${ }^{1}$ The pathophysiology of ischemia-reperfusion injury (IRI) involves the release of reactive oxygen species (ROS) and other mediators of the inflammatory response such as cytokines and adhesion molecules.
\end{abstract}

Background: Moringa oleifera is known to exhibit protection against oxidative damage due to its rich content of compounds with antioxidant activity. This study investigated the protective effect of the methanol extract of Moringa oleifera (MO) in a

Methods: Forty two wistar rats were randomly assigned to six groups of seven rats each, as follows: A, control group; B, sham-operated group; C, IR group; D, IR + low dose (200 mg/kg) MO; E, IR + high dose (400 mg/kg) MO and F, IR + Vitamin C $(200 \mathrm{mg} / \mathrm{kg})$. Unilateral ischaemia was induced by occluding the left renal artery for 45 minutes followed by rep-

Results: Moringa oleifera significantly $(\mathrm{p}<0.05)$ ameliorated IR-induced increases in malondialdehyde (MDA), protein carbonyls (PC) and advanced oxidation protein products (AOPP), while also decreasing serum BUN and Creatinine levels. Moreover, the low dose of MO caused reductions in renal NO and $\mathrm{H}_{2} \mathrm{O}_{2}$ levels, while increasing renal GPx and GST activities. Histopathology revealed marked improvement of tissue alterations induced by IR with both doses of MO.

Conclusion: Overall, the methanol extract of $M$. oleifera effectively attenuated the deleterious effects of renal IR via allevi-

Keywords: Oxidative stress, ischaemia-reperfusion, Moringa oleifera, kidneys, antioxidants.

Cite as: Akinrinde AS, Odwwole O, Akinrinmade FJ, Bolaji-Alabi FB. Nephroprotective effect of methanol extract of Moringa oleifera leaves on acute kidney injury induced by ischemia-reperfusion in rats. Afri Health Sci. 2020;20(3): 1382-1396. bttps:/ / dx.doi.org/ 10.4314/

\section{Corresponding author: \\ Akinrinde AS, \\ Department of Veterinary Physiology \\ and Biochemistry, Faculty of Veterinary \\ Medicine,University of Ibadan, \\ Nigeria \\ Phone: +234(0)7064368126 \\ E.mail: as.akinrinde@mail.ui.edu.ng; \\ leyesteve2000@yahoo.com}

These molecules recruit polymorphonuclear leucocytes into the post-ischemic tissue, while promoting injury to vascular endothelial cells via increased leucocyte-endothelial interactions. ${ }^{2}$

During ischemia, ROS such as hydrogen peroxide, superoxide and hydroxyl radicals, as well as reactive nitrogen species (RNS), including nitric oxide and peroxynitrite radicals, produce renal tissue injury via oxidative damage to proteins, lipids and DNA leading to cellular dysfunction, apoptosis and necrosis. Exacerbation of the injury often occurs following restoration of blood supply to the post-ischemic tissues due to further production of several free radicals and a typically reinforced inflammatory response. ${ }^{3}$ Therefore, preventing the production of free radicals by inhibiting the pathways for their generation remains an important strategy to protecting tissues against ischemia-reperfusion injury.

Recent investigations into the use of herbal products as natural agents against renal ischemia-reperfusion inju- 
ry have yielded encouraging results. The renoprotective effects seen with some herbs have been mainly attributed to their antioxidant and radical scavenging activities. ${ }^{4}$, Moringa oleifera is a widely recognized herb with well described nutritional, nutraceutical, and industrial values. ${ }^{6}$ It exerts multiple biological activities, including antioxidant, anti-inflammatory anti-proliferative, hepato-protective and cardio-protective functions, all of which have been attributed to its high content of important bioactive compounds, such as flavonoids, alkaloids, phytosterols and glucosinolates. ${ }^{7,8}$ Specifically, the leaves and some other parts of the Moringa plant have been found to contain high concentrations of flavonoids such as quercetin, kaempferol and apigenin and these are believed to be responsible for the potent antioxidant activity of the plant. ${ }^{9}$

Previous studies evaluated the nephroprotective properties of Moringa oleifera against gentamicin-induced; ${ }^{10,11}$ paracetamol-induced ${ }^{12}$ and nickel-induced ${ }^{13}$ nephrotoxicity. However, its protective effect against acute kidney injury induced by occlusion of vascular supply to the kidneys has not been investigated. Moreover, there is very little information in scientific literature validating the beneficial roles of herbal medications in patients undergoing surgical procedures, including kidney transplantation. Therefore, the present study was designed to evaluate the nephroprotective capacity of Moringa oleifera leaves in rats subjected to renal ischemia-reperfusion injury.

\section{Materials and methods \\ Chemicals and kits}

Vitamin C, Adrenaline, Reduced glutathione, 5, 5'-dithiobis-2- nitrobenzoic acid (DTNB), xylenol orange, hydrogen peroxide, trichloroacetic acid (TCA) and thiobarbituric acid (TBA) were purchased from Sigma Chemical Co. (St. Louis, MO, USA). Serum Urea and Creatinine kits were obtained from Randox Laboratories Limited (Crumlin, UK). All other chemicals used were of analytical grade and were obtained from British Drug Houses (Poole, Dorset, UK).

\section{Plant collection and preparation of plant extract}

Moringa oleifera leaves were harvested from the Botanical Garden, University of Ibadan, Nigeria. They were identified and authenticated at the herbarium of the Department of Botany, University of Ibadan, where a voucher specimen was also deposited (Voucher number: UIH22770). The leaves were air-dried and milled into coarse powder using an electric blender. In an initial de-fatting process, about $1.6 \mathrm{~kg}$ of the grounded sample was weighed and transferred into a glass container with $6 \mathrm{~L}$ of n-hexane. This was stirred regularly every two hours over a $72 \mathrm{~h}$ period. About $1.5 \mathrm{~kg}$ of the defatted sample was transferred into a glass container and $6 \mathrm{~L}$ of a methanol-water $(80: 20 \mathrm{v} / \mathrm{v})$ was added and allowed to stay for another 72 hours, while stirring at intervals. The solvent (now containing the extract) was filtered using Whatman No. 1 filter paper. The process was repeated with another 4L of methanol-water solvent mixture. The combined filtrate was then concentrated with the aid of rotary evaporator (Heidolph Laborota 400; Model 517-01002-002 Germany) at $40^{\circ} \mathrm{C}$, after which the resulting extract was further concentrated using a vacuum oven at $40^{\circ} \mathrm{C}$ with a pressure of $700 \mathrm{mmHg}$.

\section{Qualitative phytochemical analysis}

Chemical tests, including those for flavonoids, saponins, tannins, steroids, alkaloids, anthraquinones, cardiac glycosides and terpenoids were conducted on the methanol extract of Moringa oleifera using standard methods. 14

\section{Total phenol determination}

Total phenol content was determined with the Folin-Ciocalteu reagent according to a procedure described by Oliva et al. ${ }^{15}$ About $0.5 \mathrm{ml}$ of the diluted sample was reacted with $2.5 \mathrm{ml}$ of $0.2 \mathrm{M}$ Folin-Ciocalteu reagent for 4 $\mathrm{min}$, and then $2 \mathrm{ml}$ of saturated sodium carbonate solution was added to the reaction mixture. The absorbance readings were taken at $760 \mathrm{~nm}$ after incubation at room temperature for $2 \mathrm{~h}$. Gallic acid was used as standard, the total phenolic content was calculated from the calibration curve, and the results were expressed as mg of gallic acid equivalent per gram of dried extract.

\section{Total flavonoid determination}

Total flavonoids were quantitatively determined using the aluminum chloride colorimetric method as described by Chang et al. ${ }^{16}$ Reaction mixtures containing $100 \mathrm{ml}$ of the aqueous-methanolic extract $(1 \mathrm{mg} /$ $\mathrm{ml}$ ) were mixed with $4 \mathrm{ml}$ of distilled water, and $0.3 \mathrm{ml}$ of $5 \% \mathrm{NaNO}_{2}$ was then added and mixed thoroughly. Next, $0.3 \mathrm{ml}$ of $10 \% \mathrm{AlCl}_{3}$ solution was added. After 5 min of incubation, $2 \mathrm{ml}$ of $1 \mathrm{M} \mathrm{NaOH}$ solution was added and the final volume of the mixture was mde up to $10 \mathrm{ml}$ using double-distilled water. The mixture was then incubated for $15 \mathrm{~min}$ at room temperature, and the absorbance was measured at $510 \mathrm{~nm}$ using a spec- 
trophotometer. Rutin was used as standard; the total flavonoid content calculated from a calibration curve, and the result was expressed as milligram of rutin equivalent per gram of dried extract

\section{Animals and experimental design}

Forty two (42) healthy wistar rats (200-250 g) were procured from the Experimental Animal Unit, Faculty of Veterinary Medicine, University of Ibadan, Nigeria. They were housed in plastic cages in a well-ventilated animal house and maintained on standard rat chow and clean water ad libitum throughout the experimental period. The handling of the animals was according to the guidelines outlined in the Guide for the Care and Use of Laboratory Animals prepared by the National Academy of Science and published by the National Institute of Health. ${ }^{17}$ Institutional approval was obtained from the Animal Care and Use Research Ethics Committee, University of Ibadan, Ibadan, Nigeria (Approval number: UI-ACUREC/18/0099)

After a week of acclimation, the rats were randomly allocated to six groups ( $\mathrm{n}=7$ rats per group) as follows: Group A: Negative control group; healthy rats given clean tap water for 7 days.

Group B: Sham control group; rats given clean tap water for 7 days and then subjected to abdominal flank incision without occlusion of renal vessels.

Group C: Ischemia-reperfusion (IR) group

Group D: rats pre-treated with Moringa oleifera extract (200 mg/kg) for 7 days prior to IR induction

Group E: rats pre-treated with Moringa oleifera extract $(400 \mathrm{mg} / \mathrm{kg}$ ) for 7 days prior to IR induction

Group F: rats pre-treated with Vitamin C (200 mg/kg) for 7 days prior to IR induction.

The selected dosages of the Moringa oleifera extract and Vitamin $C$ were based on previous studies by Kirisattayakul et al. ${ }^{18}$ and Akinrinmade et al. ${ }^{19}$, respectively.

\section{Induction of renal ischemia-reperfusion injury}

Each rat subjected to IR was initially anaesthetized with Ketamine $(40 \mathrm{mg} / \mathrm{kg}$ ) and Xylazine $(5 \mathrm{mg} / \mathrm{kg})$ administered intramuscularly. The hair in the left flank region of the abdomen was clipped and the area was aseptically prepared by disinfection with a chlorhexidine and alcohol. A flank incision (about $3 \mathrm{~cm}$ ) was made and the left kidney was exteriorized with non-toothed thumb forceps. The renal artery was isolated and occluded with an atraumatic vascular clip for 45 minutes. Thereafter, the clamps were removed and reperfusion was allowed for an initial 30 minutes before closing the incision site in layers. Reperfusion was then continued for 24 hours prior to sacrifice. Sham-operated rats only went through a flank incision without ischemia and reperfusion. At the end of the reperfusion period, blood was collected from the retro-orbital plexus into plain sample tubes and the rats were sacrificed by cervical dislocation. The left kidney was harvested, weighed and processed for biochemical analysis. Small portions of the kidney was cut and placed immediately in 10\% buffered formalin for histopathological examination.

\section{Biochemical analysis}

Blood used for the preparation of serum was initially collected into anti-coagulant free plastic tubes and allowed to clot at room temperature. The blood samples were centrifuged within $3 \mathrm{~h}$ of collection at $3000 \mathrm{rpm}$ for 10 minutes. The serum samples were later stored at a temperature of $-20^{\circ} \mathrm{C}$ for biochemical analysis. The serum was used for the measurement of urea and creatinine concentrations, using commercially obtained kits (Randox Laboratories, Crumlin, UK).

The kidney tissues were rinsed in $0.9 \% \mathrm{NaCl}$ and later homogenized in $50 \mathrm{mM}$ Tris- $\mathrm{HCl}$ buffer ( $\mathrm{pH}$ 7.4) containing $1.15 \% \mathrm{KCl}$. The homogenate was subjected to cold centrifugation at $4^{\circ} \mathrm{C}$ at a speed of $12,000 \mathrm{x}$ $\mathrm{g}$ for $10 \mathrm{~min}$. The supernatant was collected and used for the biochemical assays. Protein concentration was determined by Biuret method as described by Gornal et al. ${ }^{20}$ Lipid peroxidation was evaluated by measuring malondialdehyde (MDA) concentration, in $\mu \mathrm{mol}$ MDA formed/mg protein, according to the method described by Varshney \& Kale ${ }^{21}$, using a molar extinction coefficient of $1.56 \times 10^{5} \mathrm{M}-1 \mathrm{~cm}-1$. Hydrogen peroxide generation was estimated using the method of Wolff. ${ }^{22}$ Protein carbonyl content was determined using the method described by Reznick and Packer ${ }^{23}$. Advanced oxidation protein products (AOPP) were estimated according to the method described by Kayali et al. ${ }^{24}$ Nitric oxide (NO) content of the tissues was measured as nitrite levels using the method described by Olaleye et al. ${ }^{25}$ Reduced glutathione concentration (GSH) was determined by the method of Beutler et al. ${ }^{26}$ The tissue content of protein thiols (P-SH) and non-protein thiols (NP-SH) were determined using the method of Ellman ${ }^{27}$. Glutathione-S-transferase (GST) activity was measured by the method of Habig et al. ${ }^{28}$ using 1-chloro-2, 4-dinitrobenzene as substrate. Glutathione peroxidase (GPx) activity was evaluated using the method described by Rotruck et al. ${ }^{29}$. Superoxide dismutase (SOD) activity was determined by measuring the inhibition of the auto-oxidation of epinephrine at $\mathrm{pH} 10.2$ as described by Misra and Fridovich ${ }^{30}$ with slight modifications introduced by Oyagbemi et al. ${ }^{31}$ 


\section{Evaluation of renal histopathology}

Small pieces of the kidney tissues were immediately collected in $10 \%$ buffered formalin, after the sacrifice of animals for proper fixation. They were then embedded in paraffin wax and sections 5-6 $\mu \mathrm{m}$ thick were stained with either hematoxylin and eosin $(\mathrm{H} \& \mathrm{E})^{32}$ or Periodic acid Schiff (PAS). Assessment of histopathological lesions was done using the EGTI scoring system ${ }^{33}$, which quantitatively scores Endothelial (E), Glomerular (G), Tubular (T) and Interstitial (I) lesions on a scale of 0 to 4. Lesions scored as 0 indicates no damage, while lesions of the highest severity are scored as 4 .

\section{Statistical analysis}

Values were expressed as mean \pm standard deviation of 7 animals per group, using Microsoft Excel Software.
Differences between groups were computed using Student's t-test and across the experimental groups, one-way analysis of variance (ANOVA) with Least Significant Difference (LSD) post-hoc analysis using GraphPad Prism software (version 7.00). P values less than 0.05 were considered statistically significant.

\section{Results}

Phytochemical composition of Moringa oleifera extract

As presented in Table 1a, phytochemical screening of the M. oleifera extract revealed that the predominant phytoconstituents were flavonoids, saponins and tannins. Other chemicals present included alkaloids, phenols and steroids, while anthraquinones, glycosides and terpenoids were not detected.

Table 1a: Phytochemicals present in Moringa oleifera methanol extract.

\begin{tabular}{l|c}
\hline Compounds & Test Inference \\
\hline Saponins & ++ \\
Flavonoids & ++ \\
Tannins & ++ \\
Phenols & + \\
Steroids & + \\
Alkaloids & + \\
Anthraquinones & - \\
Cardiac glycosides & - \\
Terpenoids & - \\
\hline
\end{tabular}

+ , moderately present; ++, highly present; -, absent

The total phenol content of the extract, calculated from the calibration curve: $\mathrm{y}=0.001 \mathrm{x}-0.026 ; \mathrm{R}^{2}=0.988$ was $65.00 \pm 4.58 \mathrm{mg}$ gallic acid equivalent per gram of dry extract, while the total flavonoid content from the calibration curve: $\mathrm{y}=0.0009 \mathrm{x}+0.008 ; \mathrm{R}^{2}=0.956$ ) was $372.59 \pm 8.06 \mathrm{mg}$ rutin equivalent per gram of dry extract (Table 1b), indicating that flavonoids were a predominant phytochemical in the extract. 
Table 1b: Total phenolic and flavonoid contents of the aqueous-methanol extract of Moringa oleifera leaves

\begin{tabular}{c|c}
\hline Phytoconstituent & Quantity \\
\hline $\begin{array}{c}\text { Total Flavonoids } \\
\text { (mg rutin equivalent/g of } \\
\text { extract) }\end{array}$ & $372.59 \pm 8.06$ \\
$\begin{array}{c}\text { Total Phenols } \\
\text { ( } m g \text { gallic acid }\end{array}$ & $65.00 \pm 4.58$ \\
equivalent/g of extract) & \\
\hline
\end{tabular}

Body and organ weights

Changes in body weights measured before and after the experiments are presented as percentage weight gain in Table 2. The results indicated weight gains in rats in the control groups, as well as those treated with $M$. oleifera. However, no changes in body weights were noticeable in rats that underwent IR alone and those pre-treated with Vitamin C.

Table 2: Effect of methanol extract of Moringa oleifera on relative kidney weights in rats undergoing renal ischemia-reperfusion injury

\begin{tabular}{c|cc}
\hline Groups & Percentage weight gain (\%) & Relative kidney weights (\%) \\
\hline A & $7.36 \pm 2.26$ & $0.28 \pm 0.03$ \\
B & $5.08 \pm 0.79$ & $0.29 \pm 0.03$ \\
C & $0.00 \pm 0.00^{a, b}$ & $0.36 \pm 0.02^{a, b}$ \\
D & $7.18 \pm 2.79^{c}$ & $0.33 \pm 0.03$ \\
E & $4.89 \pm 0.44^{c}$ & $0.34 \pm 0.03$ \\
F & $0.00 \pm 0.00$ & $0.36 \pm 0.02$ \\
\hline
\end{tabular}

Values are expressed as mean \pm standard deviation $(n=7)$

- Significant ( $p<0.05)$ compared to normal controls

- Significant ( $p<0.05)$ compared to sham controls

- Significant ( $p<0.05$ ) compared to IR group

$A=$ Normal control; $B=$ Sham control; $C=I R$ group; $D=I R+M O(200 \mathrm{mg} / \mathrm{kg}) ; E=I R+M O(400$ $\mathrm{mg} / \mathrm{kg}) ; \mathrm{F}=\mathrm{IR}+\operatorname{Vit} . C(200 \mathrm{mg} / \mathrm{kg})$

The relative kidney weights of the rats in the different groups are also presented in Table 2 . When compared with the normal or sham controls, kidney weights were significantly increased $(\mathrm{p}<0.05)$ in all the groups undergoing IR, irrespective of the treatments administered.

\section{Markers of renal dysfunction}

The effects of $M$. oleifera extract on markers of renal in- jury and function are shown in Table 3. It was observed that IR significantly $(\mathrm{p}<0.05)$ increased the serum levels of Blood urea nitrogen (BUN) and creatinine, when compared with the controls. However, $M$. oleifera at the dose of $400 \mathrm{mg} / \mathrm{kg}$ b.w. significantly $(\mathrm{P}<0.05)$ reduced serum levels of BUN and creatinine, compared to the IR group. This effect was similar to what was obtained with Vitamin C treatment. 
Table 3: Effect of methanol extract of Moringa oleifera on Blood urea nitrogen (BUN) and serum creatinine levels in rats undergoing renal ischemiareperfusion injury

\begin{tabular}{c|cc}
\hline Treatment & Blood Urea Nitrogen $(\mathrm{mg} / \mathrm{dl})$ & Serum Creatinine $(\mathrm{mg} / \mathrm{dl})$ \\
\hline A & $17.75 \pm 1.03$ & $0.65 \pm 0.10$ \\
B & $17.85 \pm 1.25$ & $0.64 \pm 0.19$ \\
C & $20.25 \pm 1.08^{a, b}$ & $0.88 \pm 0.09^{a, b}$ \\
D & $19.37 \pm 1.12$ & $0.79 \pm 0.07$ \\
E & $17.67 \pm 1.22^{c}$ & $0.70 \pm 0.10$ \\
F & $16.72 \pm 0.698^{c}$ & $0.69 \pm 0.17 c$ \\
\hline
\end{tabular}

Values are expressed as mean \pm standard deviation $(n=7)$

- Significant ( $p<0.05)$ compared to normal controls

- Significant ( $p<0.05$ ) compared to sham controls

- Significant ( $p<0.05$ ) compared to IR group

$A=$ Normal control; $B=$ Sham control; $C=I R$ group; $D=I R+M O(200 \mathrm{mg} / \mathrm{kg}) ; E=I R+M O(400$

$\mathrm{mg} / \mathrm{kg}) ; \mathrm{F}=\mathrm{IR}+\operatorname{Vit} . C(200 \mathrm{mg} / \mathrm{kg})$

Renal markers of oxidative stress

Table 4 shows the effect of $M$. oleifera on hydrogen peroxide $\left(\mathrm{H}_{2} \mathrm{O}_{2}\right)$ generation and nitric oxide (NO) production in the kidneys of rats subjected to renal IR injury. Ischemia-reperfusion produced significant $(\mathrm{p}<0.05)$ increases in the tissue levels of $\mathrm{H}_{2} \mathrm{O}_{2}$ and $\mathrm{NO}$, when compared with the control groups. Moringa oleifera at $200 \mathrm{mg} / \mathrm{kg}$ b.w. significantly $(\mathrm{p}<0.05)$ reduced renal NO levels, when compared with the IR group, whereas Vitamin $C$ caused significant $(\mathrm{p}<0.05)$ reduction in renal contents of both $\mathrm{H}_{2} \mathrm{O}_{2}$ and $\mathrm{NO}$ levels.

Table 4: Effect of methanol extract of Moringa oleifera on hydrogen peroxide and nitric oxide levels in renal tissues of rats undergoing renal ischemia-reperfusion injury

\begin{tabular}{c|cl}
\hline Treatment & Hydrogen peroxide & Nitric oxide \\
\hline A & $58.8 \pm 7.53$ & $0.68 \pm 0.18$ \\
B & $58.02 \pm 5.11$ & $0.78 \pm 0.12$ \\
C & $73.88 \pm 4.57^{\circ, \mathrm{b}}$ & $1.30 \pm 0.15^{\circ, \mathrm{b}}$ \\
D & $71.48 \pm 4.36$ & $1.06 \pm 0.13^{c}$ \\
E & $78.73 \pm 6.30$ & $1.28 \pm 0.13$ \\
F & $62.43 \pm 6.01 \mathrm{c}$ & $0.93 \pm 0.15$ \\
\hline
\end{tabular}

Values are expressed as mean \pm standard deviation $(n=7)$

- Significant ( $p<0.05)$ compared to normal controls

- Significant $(p<0.05)$ compared to sham controls

Significant ( $p<0.05$ ) compared to IR group

$A=$ Normal control; $B=$ Sham control; $C=I R$ group; $D=I R+M O(200 \mathrm{mg} / \mathrm{kg}) ; E=I R+M O(400$

$\mathrm{mg} / \mathrm{kg}) ; \mathrm{F}=\mathrm{IR}+\operatorname{Vit} . C(200 \mathrm{mg} / \mathrm{kg})$ 


\section{Renal markers of oxidative stress}

As presented in Fig. 1, rats subjected to renal IR injury showed significant $(\mathrm{p}<0.05)$ increases in the levels of malondialdehyde (MDA) and advanced oxidation protein products (AOPP) in the kidney, when compared with the controls. Levels of protein carbonyls (PC) were, however, not affected as a result of IR. When compared with the IR group, $M$. oleifera, caused significant $(p<0.05)$ reduction in renal MDA and AOPP, while also producing significant $(\mathrm{p}<0.05)$ reduction in renal PC content, compared with both the IR and control groups. This same trend was observed in rats treated with Vitamin C.
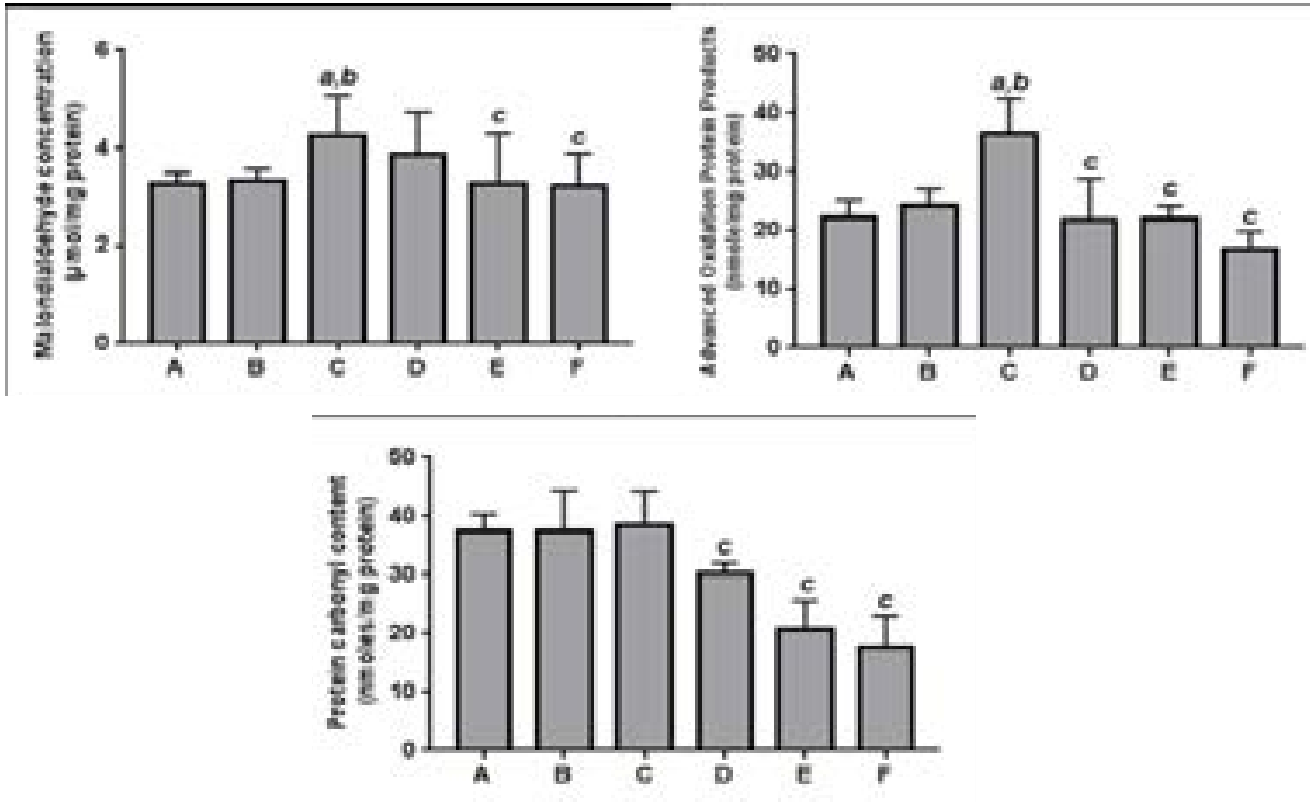

Figure 1: Effect of methanol extract of Moringa oleifera on products of lipid and protein oxidation in renal tissues of rats undergoing renal ischemia-reperfusion injury.

Values are expressed as meantstandard deviation $(n=7)$

a Significant $(p<0.05)$ compared to normal controls

b Significant $(p<0.05)$ compared to sham controls

c Significant ( $p<0.05)$ compared to IR group

$A=$ Normal control; $B=$ Sham control; $C=I R$ group; $D=I R+M O(200 \mathrm{mg} / \mathrm{kg}) ; E=I R+M O(400$ $\mathrm{mg} / \mathrm{kg}) ; \mathrm{F}=\mathrm{IR}+$ Vit. $C(200 \mathrm{mg} / \mathrm{kg})$

\section{Renal antioxidant status}

The effects of the Moringa extract on tissue level of thiols are presented in Fig. 2. Ischemia and reperfusion of the kidney resulted in significant $(\mathrm{p}<0.05)$ reduction in the level of protein thiols (PT), when compared with the controls, although levels of reduced glutathione (GSH) and non-protein thiols (NPT) were not affected. Pre-treatment with $M$. oleifera at $400 \mathrm{mg} / \mathrm{kg}$ b.w. as well as Vitamin C (200 mg/kg b.w.) caused significant $(\mathrm{p}<0.05)$ enhancement of renal PT and GSH levels when compared with the IR group. 

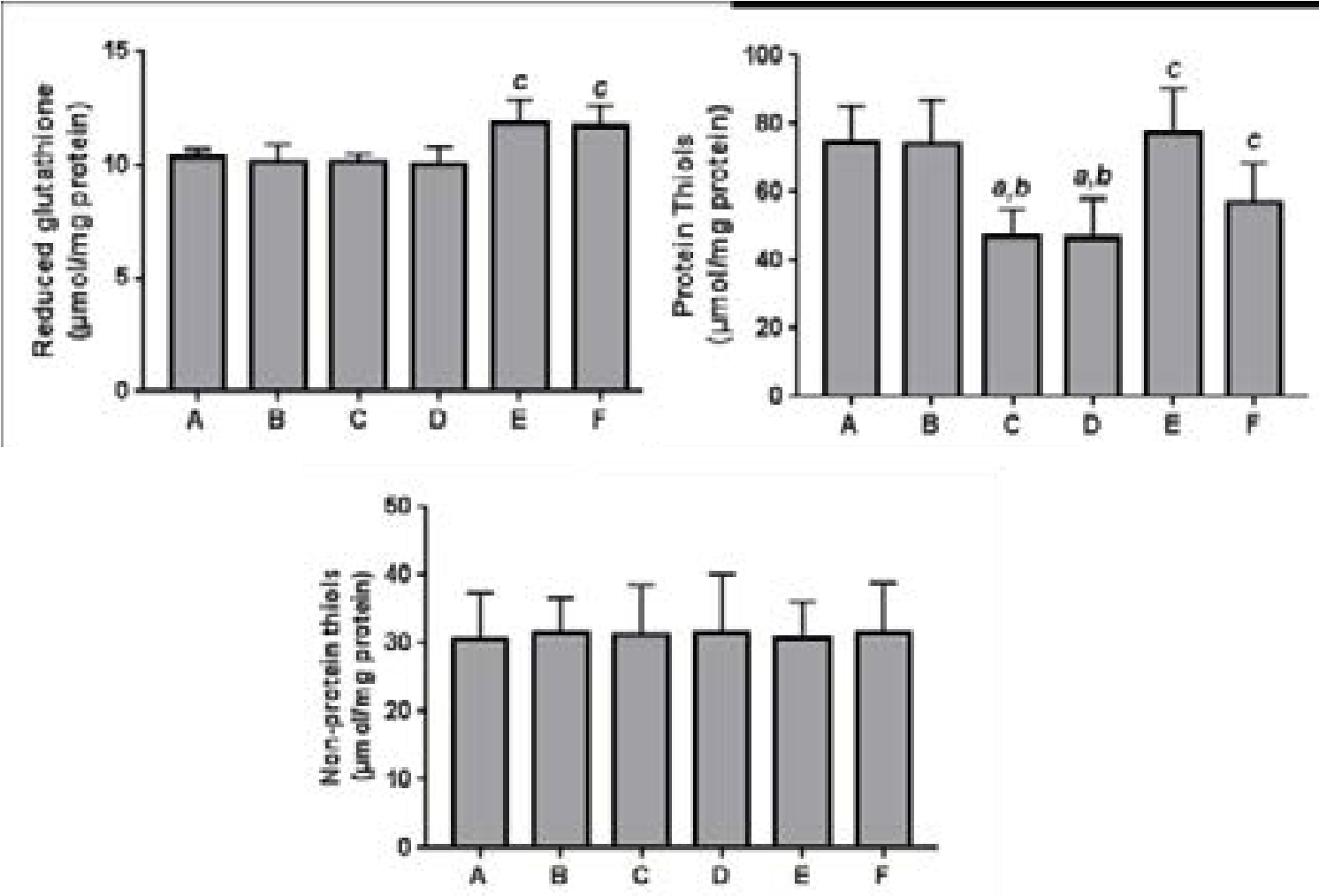

Figure 2: Effect of methanol extract of Moringa oleifera on thiol groups in renal tissues of rats undergoing renal ischemia-reperfusion injury.

Values are expressed as meantstandard deviation $(n=7)$

a Significant ( $p<0.05$ ) compared to normal controls

b Significant $(p<0.05)$ compared to sham controls

${ }^{c}$ Significant $(p<0.05)$ compared to IR group

$A=$ Normal control; $B=$ Sham control; $C=I R$ group; $D=I R+M O(200 \mathrm{mg} / \mathrm{kg}) ; E=I R+M O(400$ $\mathrm{mg} / \mathrm{kg}) ; \mathrm{F}=\mathrm{IR}+$ Vit. $C(200 \mathrm{mg} / \mathrm{kg})$

The renal activities of Glutathione peroxidase (GPx) and Glutathione S-transferase (GST) were significantly $(\mathrm{p}<0.05)$ inhibited when rats were subjected to IR injury alone in comparison with the control group (Table 5). In contrast, pre-treatment with the lower dose of the Moringa extract, as well as Vitamin C significant- ly $(p<0.05)$ enhanced the activities of these enzymes, when compared with the IR group. On the other hand, the rats pre-treated with $M$. oleifera at $400 \mathrm{mg} / \mathrm{kg}$ b.w. presented with much lower activities of GPx and GST compared to even the control groups. The renal activity of superoxide dismutase (SOD) was largely unaltered in all the groups. 
Table 5: Effect of methanol extract of Moringa oleifera on antioxidant enzymes in renal tissues of rats undergoing renal ischemia-reperfusion injury

\begin{tabular}{c|ccc}
\hline Treatment & $\begin{array}{c}\text { Glutathione S- } \\
\text { transferase }\end{array}$ & $\begin{array}{c}\text { Glutathione } \\
\text { peroxidase }\end{array}$ & $\begin{array}{c}\text { Superoxide } \\
\text { dismutase }\end{array}$ \\
\hline A & $3.14 \pm 0.81$ & $17.82 \pm 3.67$ & $8.51 \pm 0.11$ \\
B & $3.38 \pm 0.68$ & $17.71 \pm 3.39$ & $8.51 \pm 0.09$ \\
C & $2.19 \pm 0.53^{a, b}$ & $9.08 \pm 1.14^{a, b}$ & $8.49 \pm 0.05$ \\
D & $3.89 \pm 1.12^{c}$ & $21.14 \pm 5.70 c$ & $8.52 \pm 0.06$ \\
E & $2.22 \pm 0.61$ & $9.23 \pm 1.58$ & $8.52 \pm 0.08$ \\
$F$ & $3.47 \pm 1.33^{c}$ & $16.65 \pm 5.61^{c}$ & $8.55 \pm 0.05 c$ \\
\hline
\end{tabular}

Values are expressed as mean \pm standard deviation $(n=7)$

a Significant ( $p<0.05)$ compared to normal controls

b Significant ( $p<0.05)$ compared to sham controls

${ }^{c}$ Significant ( $\left.p<0.05\right)$ compared to IR group

$A=$ Normal control; $B=$ Sham control; $C=I R$ group; $D=I R+M O(200 \mathrm{mg} / \mathrm{kg}) ; E=I R+M O(400$

$\mathrm{mg} / \mathrm{kg}) ; \mathrm{F}=\mathrm{IR}+$ Vit. $C(200 \mathrm{mg} / \mathrm{kg})$

\section{Histopathology}

The photomicrographs of H\&E staining (Fig. 3) showed that the kidneys in the normal and sham control groups presented regular architecture with normal appearance of glomeruli (white arrow), capsular spaces and normal tubular arrangement and interstitial spaces (Figs. 3C and $3 \mathrm{~B}$ ) In the IR group, the kidneys presented with very poor architecture with the renal cortex showing glomerular sclerosis and necrosis (black arrow), while few glomeruli presented with hyperplasia of mesangial cells. The renal tubules also show necrosis (blue arrow) and the interstitial spaces appear infiltrated by inflammatory cells (Fig. 3C). In contrast, the kidneys from the rats treated with Moringa oleifera or Vitamin C (Figs. 3 $\mathrm{D}, \mathrm{E}$ and F) showed several normal glomeruli (white arrow) with the interstitial spaces also appearing normal in most parts, although there were still moderate degrees of tubular necrosis (blue arrow) and dilation (red arrow) and inflammatory cell infiltration. 


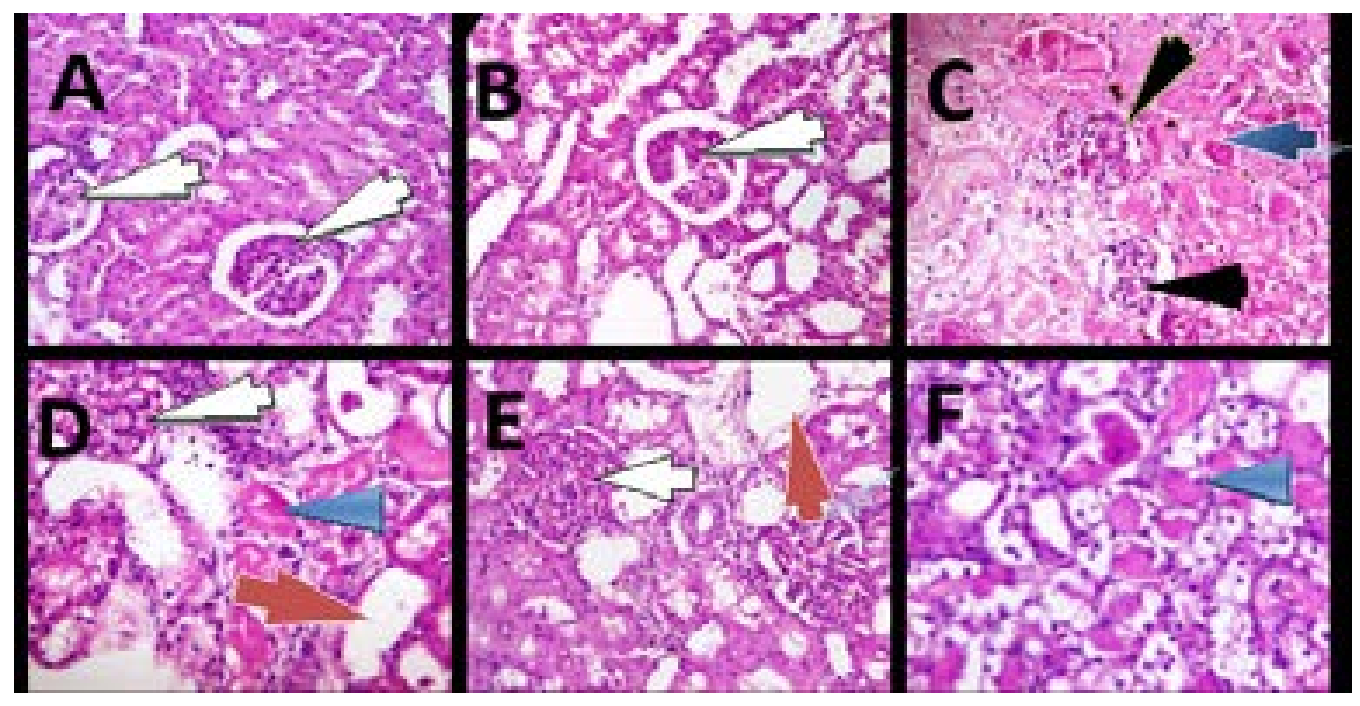

Figure 3: Representative photomicrographs of kidney histology (H\&E; magnification: $x 400$ ). $A=$ Normal control; $B=$ Sham control; $C=I R$ group; $D=I R+M O(200 \mathrm{mg} / \mathrm{kg}) ; E=I R+M O(400$ $\mathrm{mg} / \mathrm{kg}) ; \mathrm{F}=\mathrm{IR}+\mathrm{Vit} . \mathrm{C}(200 \mathrm{mg} / \mathrm{kg})$. The white arrows show normal glomeruli; black arrows show severely damaged glomeruli with severe necrosis and sclerosis; blue arrows show areas of tubular necrosis.

The photomicrographs of the Periodic acid Schiff (PAS) staining of the kidneys revealed thickened glomeruli basement membrane and renal tubules with loss of brush border in the tubular epithelium as the major pathological lesions in the IR group (Fig. 4). No significant lesions were revealed by PAS in control and treated groups.

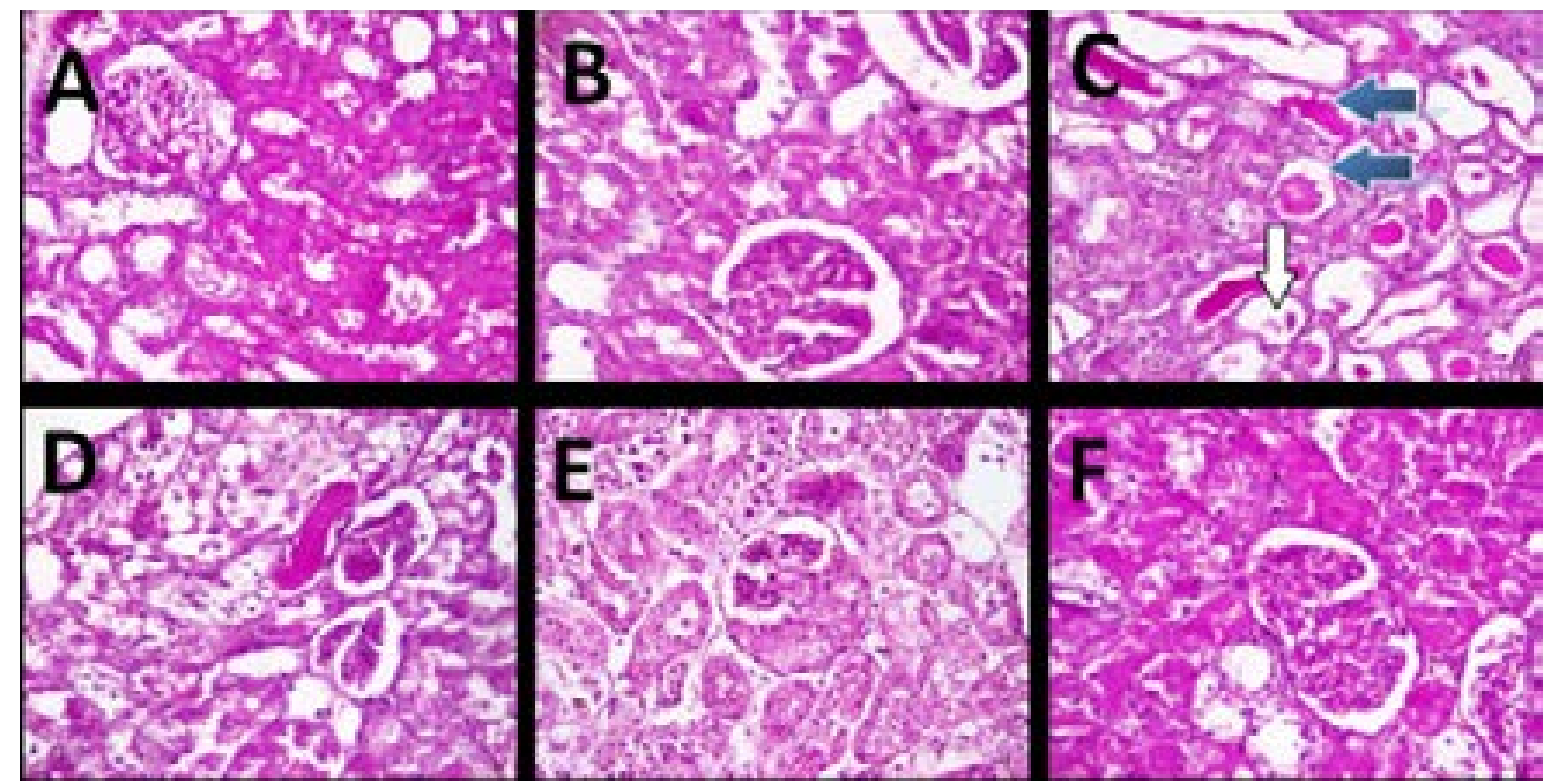

Figure 4: Representative photomicrographs of kidney histology (PAS; magnification: $\times 400) . A=$ Normal control; $B=$ Sham control; $C=I R$ group; $D=I R+M O(200 \mathrm{mg} / \mathrm{kg}) ; E=I R+M O(400$ $\mathrm{mg} / \mathrm{kg}) ; \mathrm{F}=\mathrm{IR}+\operatorname{Vit} . C(200 \mathrm{mg} / \mathrm{kg})$. The white arrow shows thickened glomerular basement membrane; blue arrows show loss of tubular brush border.

The severity of the observed lesions in the various groups was confirmed by pathological scoring using the EGTI scoring system (Table 6). The scoring revealed significantly higher levels of damage in endothelial, glomerular, tubular and interstitial lesions in the IR group compared to the control groups, which showed no significant lesions. Rats pre-treated with either $M$. oleifera or Vitamin C, however, presented with significantly lower severity scores in all regions of the kidneys examined, indicating significant attenuation of IR-induced injury. 
Table 6: EGTI score of histopathological findings in the renal tissues of rats

\begin{tabular}{|c|c|c|c|c|}
\hline Group & $\begin{array}{l}\text { Endothelial } \\
\text { lesions }\end{array}$ & $\begin{array}{l}\text { Glomerular } \\
\text { lesions }\end{array}$ & $\begin{array}{l}\text { Tubular } \\
\text { lesions }\end{array}$ & $\begin{array}{l}\text { Interstitial } \\
\text { lesions }\end{array}$ \\
\hline $\begin{array}{l}\text { Normal } \\
\text { control }\end{array}$ & $0.0 \pm 0.0$ & $0.0 \pm 0.0$ & $0.0 \pm 0.0$ & $0.0 \pm 0.0$ \\
\hline Sham control & $0.0 \pm 0.0$ & $0.0 \pm 0.0$ & $0.0 \pm 0.0$ & $0.0 \pm 0.0$ \\
\hline IR-group & $3.82 \pm 0.40^{a, b}$ & $3.00 \pm 1.44^{a, b}$ & $3.17 \pm 0.92^{a, b}$ & $2.33 \pm 0.96^{a, b}$ \\
\hline MO Low dose & $1.67 \pm 0.48$ & $0.70 \pm 0.72$ & $3.00 \pm 1.44^{c}$ & $1.22 \pm 0.42^{c}$ \\
\hline MO High dose & $1.00 \pm 0.00$ & $1.39 \pm 0.78^{c}$ & $3.17 \pm 0.92^{c}$ & $1.17 \pm 0.38$ \\
\hline Vit. $C$ group & $1.26 \pm 0.59$ & $1.11 \pm 0.75$ & $2.33 \pm 0.96$ & $0.70 \pm 0.47$ \\
\hline \multicolumn{5}{|c|}{$\begin{array}{l}\text { Values are expressed as mean } \pm \text { standard deviation }(n=7) \\
\text { a Significant }(p<0.05) \text { compared to normal controls } \\
\text { b Significant }(p<0.05) \text { compared to sham controls } \\
\text { c Significant }(p<0.05) \text { compared to IR group } \\
\text { A = Normal control; B = Sham control; } C \text { = IR group; } D=I R+M O(200 \mathrm{mg} / \mathrm{kg}) ; E=I R+M O(400 \\
\mathrm{mg} / \mathrm{kg}) ; F=I R+V i t . C(200 \mathrm{mg} / \mathrm{kg})\end{array}$} \\
\hline
\end{tabular}

\section{Discussion}

Prevention of renal tissue damage due to ischemia and reperfusion is key to the final success of renal surgeries such as transplantation and resection of renal tumors. Ischemia and subsequent reperfusion injury are the leading causes of post-operative acute or chronic renal failure. ${ }^{34}$ In this study we evaluated the potential nephro-protective effects of pre-treatment of rats with a flavonoid-rich fraction of Moringa oleifera before experimental iduction of ischemia-reperfusion (IR) injury. In the present study, occlusion of renal vessels for 45 minutes and restoration of blood supply over a 24-hour period led to significant increases in the serum levels of key functional markers of renal injury, including creatinine and urea, when compared to control rats. Increased levels of these by-products of metabolism normally reflect a compromise of the glomerular filtration capacity, likely due to impairment of the integrity of the glomerular filtration membrane. ${ }^{35}$ Indeed, this finding was confirmed by the existence of pathological lesions in the histological sections of the kidneys of rats subjected to IR.

Histopathological examination of renal tissues following IR revealed the occurrence of glomerular lesions including sclerosis and necrosis as well as hyperplasia of mesangial cells located in the glomerular tuft between capillary loops. Tubular lesions including necrosis were also observed, while there was inflammatory cell infil- tration of the interstitial spaces. The EGTI pathology scoring of the renal lesions, however, showed that the tubular portions of the nephrons appeared to be most affected by IR.

Interestingly, our findings showed significant improvement in the appearance of renal histology in rats that were pre-treated with the Moringa oleifera fraction. Rats taking either doses of the extract showed fewer glomerular lesions and milder inflammation which was also reflected in better EGTI indices. The tissue protective ability of the extract was also indicated in the dose-dependent reduction in serum levels of BUN and creatinine in rats pre-treated with either doses of the extract. This shows that more glomeruli were preserved when rats were fed with $M$. oleifera, thus retaining their filtration capacities and ensuring the excretion of urea and creatinine through urine. ${ }^{36}$ This finding is in contrast to the report of Oyagbemi et al. ${ }^{37}$ who utilized similar doses of the methanol extract of $M$. oleifera (200 and $400 \mathrm{mg} / \mathrm{kg}$ b.w.), but revealed that the extract caused dose-dependent increases in serum BUN and creatinine, when administered orally for 8 weeks. This effect could be due to the longer duration of administration, suggesting that treatment with the extract for prolonged treatments must be advised with caution. Similar to the findings from the present study, Nafiu et al. ${ }^{11}$ also observed significant reduction in serum creatinine levels when gentamicin exposed rats were treated with 200 
and $400 \mathrm{mg} / \mathrm{kg}$ doses of the ethanol extract of Moringa oleifera seeds, suggesting that nephroprotective agents may be present in both the ethanol and methanol extracts of the plant. They performed IR spectral analysis of the ethanol extract revealing the presence of polyunsaturated fatty acids such as oleic and linoleic acids which were thought to contribute to the nephroprotective action of the ethanol extract. One limitation of the present study is that the measurement of the urine levels of the renal function parameters was not included in our study. For future studies, this might enable better judgment of the filtration capacity of the kidneys.

One major mechanism underlying the tissue damage usually observed during IR is the generation of reactive oxygen species (ROS) including superoxide, nitric oxide and hydroxyl radicals ${ }^{38,39}$, with resultant oxidative stress. Superoxide production is markedly enhanced during reperfusion by the conversion of xanthine dehydrogenase to xanthine oxidase with increase in free electrons in the mitochondria. Superoxide radicals then participate in reactions leading to formation of hydroxyl radicals. It can also combine with nitric oxide to produce the highly toxic peroxynitrite radical. ${ }^{40,41}$ ROS produce oxidative injury by attacking critical sites in lipids, proteins and DNA, while also reducing the levels of tissue antioxidants. In this study, rats in the IR group exhibited significant increases in the renal levels of hydrogen peroxide and nitric oxide as evidences of ROS generation. In addition, there were increased levels of MDA and AOPP, both indicators of increased oxidative modifications of lipids and proteins, respectively. Malondialdehyde is a product of decomposition of lipid peroxides formed during lipid peroxidation ${ }^{42}$, while AOPP, also described as dityrosines, contain cross-linked protein products formed as a result of disulphide links following low-level oxidative reactions. The presence of AOPP is thought to be a better indicator of oxidative stress.

Further evidence of oxidative stress in this study was the depletion in the activities of antioxidant enzymes, including glutathione S-transferase and Glutathione peroxidase, as well as reduced levels of protein thiols. Reactive oxygen species are known to easily react with thiol compounds in the protein moieties of cells, especially those of thiol-related proteins such as GST and GPx, leading to their inactivation. Havakhah et al. ${ }^{43}$ have previously reported reduction in thiol antioxidants in renal tissues exposed to ischemia-reperfusion injury. Endogenous antioxidant enzymes such as GST, GPx and SOD, as well as non-enzymatic molecules such as protein and non-protein thiol compounds are important contributors to the reducing ability of tissues. Superoxide dismutase catalyzes the conversion of the superoxide radical into hydrogen peroxide which can then be transformed into water and oxygen by enzymes including catalase and glutathione peroxidase. ${ }^{44}$ In this study, however, our results point to the ability of MO to contribute significantly to the cellular pool of reducing equivalents in the form of enzymatic and non-enzymatic antioxidant components. Pre-treatment with the MO extract effectively prevented the IR-induced decline in protein thiol levels, while also showing the tendency to improve the GSH pool above the values observed for the control animals.

Furthermore, the profound antioxidant activity of the extract included the possibility of its induction and/or activation of the activities of GST and GPx well above values for control animals. This effect was largely observed with the lower dose of the extract. One of the best described activities of flavonoids is their capacity to function as antioxidants, acting via several mechanisms such as scavenging of free radicals and chelation of metal ions by means of their functional hydroxyl groups. In other situations, flavonoids activate critical transcription factors e.g. NrF-2 that promote increased transcription of antioxidant genes. ${ }^{45}$ Phytochemical analyses of the Moringa oleifera fraction revealed the considerable presence of flavonoids and suggest that they probably contributed significantly to the protective effects observed with the extract.

Interestingly, rats receiving the higher dose $(400 \mathrm{mg} /$ $\mathrm{kg}$ b.w.) of the MO extract recorded lower GST and GPx activities compared to the control rats. This is despite the fact that this dose was observed to exhibit better improvement of renal function parameters. The mechanisms responsible for this variation in effects of the extract are unclear at the moment. However, the involvement of other underlying mechanisms apart from oxidative stress in the impairment of kidney function should be considered and would require further investigations. It should be noted, however, compounds with antioxidant activity may sometimes act as pro-oxidants under certain conditions, such as when administered at high dosages. ${ }^{46}$ In addition, the complexity of the composition in an extract with various types of antioxidant and pro-oxidant molecules may pose the type of findings observed in our study. It could thus be argued that the extract could tend to exert pro-oxidant effects at 
high doses. The fractionation of the methanol extract may help in identifying components of the extract with specific activities.

Although pro-oxidant effects may be viewed as detrimental to the integrity of normal tissues, it should be noted that the tendency for pro-oxidant activities and cytotoxicity by various phytochemicals, in certain conditions, may find applications in conditions requiring destruction of abnormal cells. This explains why some plants have been found useful as agents for cancer therapy. ${ }^{47}$ Nevertheless, careful consideration for selection of dosages of crude plant extracts must be made to screen for both antioxidant and pro-oxidant activities. Studies including the isolation of active compounds that could be responsible for the observed antioxidant effects in the present study are currently underway.

In this study we recorded increases in body weights of rats in the negative control and sham control groups, as well as those treated with both doses of the extract. In contrast, rats in the IR group and those pre-treated with Vit. C recorded no changes in percent weight gain during the period of the experiment. It is therefore, difficult to associate any changes in body weights to any of the treatments administered. However, it was observed that rats in all the groups subjected to renal ischemia and reperfusion, with or without pre-treatment, exhibited increases in kidney weights relative to their total body weights, suggesting the possibility of an IR-mediated effect. This finding is similar to the results obtained by Talebi et al. ${ }^{48}$, who reported that kidney weights increased significantly in groups of rats that underwent ischemia. It should be noted that these authors adopted essentially the same model of ischemia-reperfusion as the one utilized in the present study with 45 minutes ischemia and 24 hours refperfusion. Bonventre and Weinberg ${ }^{49}$ had suggested that the increase in kidney weight during ischaemia and reperfusion may be due to retention of water and nutrients by the kidney. Inflammatory processes, with recruitment of fluid and inflammatory cells may also account for the observed increases in relative kidney weights following ischaemia and reperfusion.

\section{Conclusion}

The findings from this study have indicated the nephro-protective properties of Moringa oleifera, especially at the lower dose $(200 \mathrm{mg} / \mathrm{kg})$, during oxidative injuries induced by ischemia and reperfusion of the kidney, suggesting its possible usefulness, for instance, in patients undergoing surgical manipulations involving transient occlusion and restoration of blood flow to the kidneys. Its use must be advised with close monitoring, because of potential for toxicity at high doses, as well as the tendency to elicit possible harmful herb-prescription drug interactions. Nevertheless, the proven protective benefits of Moringa oleifera against IR-induced oxidative injury, as demonstrated in this study, may justify its inclusion as integral components of the medication regimen in patients undergoing surgical procedures involving ischemia and reperfusion.

\section{Conflict of interest}

None declared.

\section{References}

1. Saat TC, Van Den Akker EK, Ijermans JNM, Dor FJMF and de Bruin RWF (2016) Improving the outcome of kidney transplantation by ameliorating renal ischemia reperfusion injury: lost in translation? J Transplant Med 2016; 14: 20.

2. Malek M, Nematbakhash M. Renal ischemia/ reperfusion injury from pathophysiology to treatment. J Renal Inj Prev. 2015; 4(2): 20-27.

3. Eltzschig $\mathrm{H}$, Eckle T. Ischemia and reperfusion - from mechanism to translation. Nat Med 2011; 17(11): 1391-1401.

4. Seth P, Kumari R, Madharan, S, Singh AK, Mani H, Banaudha KK et al. Prevention of renal ischemia-reperfusion-induced injury in rats by picroliv. Biochem Pharmacol 2000; 59: 1315-1322.

5. Singh D, Chopra K. The effect of naringin, a bioflavonoid on ischemia-reperfusion induced renal injury in rats. Pharmacol Res 2004; 50: 187-193 PubMed .

6. Abdull RAF, Ibrahim MD, Kntayya SB. Health nbenefits of Moringa oleifera. Asian Pac J Cancer Prev 2014; 15(20): 8571-8576 http://dx.doi. org/10.1155/2014/958621

7. Coppin JP, Xu Y, Chen H, Pan M, Ho C, Juliani $\mathrm{R}$ et al. Determination of flavonoids by LC/MS and anti-inflammatory activity in Moringa oleifera. J Funct Food. 2013; 5: 1892-1899. doi: 10.1016/j.jff.2013.09.010.

8. Saini RK, Shetty NP, Giridhar P. GC-FID/MS analysis of fatty acids in Indian cultivars of Moringa oleifera: Potential sources of PUFA. J Am Oil Chem Soc 2014; 91 : 1029-1034.

9. Amaglo NK, Bennett RN, Lo Curto RB, et al. Profiling selected phytochemicals and nutrients in different tissues of the multipurpose tree Moringa oleifera L., grown in Ghana. Food Chem 2010; 122: 1047-1054. doi: 10.1016/j.foodchem.2010.03.073. 
10. Ouedraogo M, Lamien-Sanon A, Ramde N, Ouedraogo AAS, Ouedraogo M, Zongo SP, et al. Protective effect of Moringa oleifera leaves against gentamicin-induced nephrotoxicity in rabbits. ExpToxicol Pathol 2013; 65(3): 335-339.

11. Nafiu AO, Akomolafe RO, Alabi QK, Idowu $\mathrm{CO}$, Odujoko OO. Effect of fatty acids from ethanol extract of Moringa oleifera seeds on kidney function impairment and oxidative stress induced by gentamicin in rats. Biomed Pharmacother. 2019; 117:109154. https:// doi.org/10.1016.j.biopha.2019.109154

12. Ijazi A, Javed I, Aslam B, Khan JA, Khaliq T, Rahman Z, et al. Nephroprotective and antioxidant effects of Moringa oleifera (Sohanjna) in paracetamol-induced nephrotoxic albino rabbits. Pak Vet J 2016; 36(3): 292-296.

13. Adeyemi OS, Elebiyo TC. Moringa oleifera supplemented diets prevented nickel-induced nephrotoxicity in Wistar rats. J Nutr Metab 2014; http://dx.doi. org/10.1155/2014958621.

14. Edeoga HO, Okwu DE, Mbaebie BO. Phytochemical Constituents of some Nigerian medicinal plants. Afr J Biotechnol 2005; 4 (7): 685-688.

15. Oliva A, Meepagala KM, Wedge DE, Harries D, Hale AL, Aliotta G, et al. Natural fungicides from Ruta graveolens L. leaves, including a new quinolone alkaloid. J Agric Food Chem 2003; 51: 890-896.

16. Chang C, Yang M, Wen H, Chern J. Estimation of total flavonoid content in propolis by two complementary colorimetric methods, J Food Drug Anal 2002; 10:178-182

17. PHS (PUBLIC HEALTH SERVICE). Public health service policy on humane care and the use of laboratory animals. US Department of Health and $\mathrm{Hu}-$ mane Services, Washington, DC. 1996; pp. 99-158.

18. Kirisattayakul W, Wattanathorn J, Tong-Un T, Muchimapura S. et al. Cerebroprotective effect of Moringa oleifera against focal ischemic stroke induced by middle cerebral artery occlusion. Oxidat Med Cell Longev, 2013; $1-10$

19. Akinrinmade JF, Akinrinde SA, Odejobi A, Oyagbemi AA. Evidence of attenuation of intestinal ischemia-reperfusion injury following pre-treatment with methanolic extracts from Chromolena odorata in rats. J Complement Integr Med 2015; 12(1): 23-32

20. Gornal AG, Bardawill JC, David MM. Determination of serum proteins by means of Biuret reaction. J Biol Chem 1949; 177:751-766.

21. Varshney R, Kale RK. Effect of calmodulin antagonists on radiation induced lipid peroxidation in microsomes. Int. J Biol. 1990; 158: 733-741.
22. Wolff SF. Ferrous ion oxidation in the presence of ferric ion indicator xylenol orange for measurement of hydrogen peroxides. Methods Enaymol 1994; 233:182189.

23. Reznick AZ, Packer L. Oxidative damage to proteins: spectrophotometric method for carbonyl assay. Methods Ensymol 1994; 233:357-363.

24. Kayali R, Cakatay U, Akcay T, Altug T. Effect of alpha-lipoic acid supplementation onmarkers of protein oxidation in post-mitotic tissues of ageing rat. Cell Biochem Funct 2006; 24(1):79-85.

25. Olaleye SB, Adaramoye OA, Erigbali PP, Adeniyi OS. Lead exposure increases oxidative stress in the gastric mucosa of $\mathrm{HCl} /$ ethanol-exposed rats. World J Gastroenterol 2007; 13: 5121-5126.

26. Beutler EO, Duron B, Kelly M. Improved method for the determination of blood glutathione. $J$ Lab Clin Med 1963; 61:882-888.

27. Ellman GL. Tissue sulfhydryl groups. Arch Biochem Biophys 1959; 82(1): 70-77.

28. Habig WH, Pabst MJ, Jacoby WB. Glutathione-S-transferase activity: the enzymic step in mercapturic acid formation. J Biol Chem 1974; 249:130-139. 29. Rotruck JT, Pope AL, Ganther HE, Swanson AB, Hafeman DG, Hoekstra WG. Selenium: biochemical role as a component of glutathione peroxidase. Science 1973; 179: 588-590 PubMed.

30. Misra HP, Fridovich I. The role of superoxide anion in the autooxidation of epinephrine and a simple assay for superoxide dismutase. J Biol. Chem 1972; 247:31703175.

31. Oyagbemi AA, Omobowale TO, Akinrinde AS, Saba AB, Ogunpolu BS, Daramola O. Lack of reversal of oxidative damage in renal tissues of lead acetate-treated rats. Environ Toxicol 2015; 30:1235-1243 PubMed .

32. Drury RA, Wallington EA, Cancerson R. Carlton's Histopathological Techniques ( $4^{\text {th }}$ ed.). Oxford, UK: Oxford University Press, 1976.

33. Khalid U, Pino-Chavez G, Nesargikar P, Jenkins $\mathrm{RH}$ et al. Kidney ischaemia reperfusion injury in the rat: the EGTI scoring system as a valid and reliable tool for histological assessment. J Histol Histopathol 2016; 3 (1) 1-7.

34. Secin FP. Importance and Limits of ischemia in renal partial surgery: Experimental and Clinical Research. Adv Urol 2008; Doi: 10.1155/2008/102461

35. Tavafi M, Ahmadvand H, Tamijidipoor A, Delfan B, Khalatbari AR. Satureja khozestanica essential oil ameliorates progression of diabetic nephropathy in uninephrectomized diabetic rats. Tissue Cell 2011; 43(1): 45 PubMed -51. 
36. Corbett JV. Laboratory tests and diagnostic procedures with nursing diagnoses. $7^{\text {th }} \mathrm{Ed}$. 2008; 90-107

37. Oyagbemi AA, Omobowale TO, Azeez IO, Abiola JO, Adedokun RA, Nottidge HO. Toxicological valuations of methanolic extract of Moringa oleifera leaves in liver and kidney of male wistar rats. J Basic Clin Physiol Pharmacol 2013; 24(4): 307-312.

38. Pasupathy S, Hormer-Vanniasinkam S. Ischemic pre-conditioning protects against ischemia-reperfusion injury: emerging concepts. European J V asc Endovasc Surg 2005; 29(2): 106-115.

39. Orvieto MA, Zorn KC, Mendiola FP et al. Ischemia pre-conditioning does not confer resilience to warm ischemia in a solitary porcine kidney model. Urology 2007; 69(5): 984-987.

40. Masaki Y, Kumano K, Endo T et al. Protective effect of nicaraven against prolonged cold kidney preservation and reperfusion injury. Transplant Proc. 1998; 30(7): 3758-3760

41. Doi K, Suzuki Y, Nakao A, Fujita T, Noiri E. Radical scavenger edaravone developed for clinical use ameliorates ischemia/reperfusion injury in rat kidney. Kidney Int. 2004; 65(5): 1714-1723.

42. Raghuvanshi R, Kaul A, Bhakuni P, Mishra A, Misra MK. Xanthine oxidase as a marker of myocardial infarction. Indian J Clin Biochem 2007; 22: 90-92.

43. Havakhah SH, Sadeghnia HR, Hajzadeh MR,
Mohammadian Roshan N, Shafiee S et al. Effect of Nigella sativa on ischemia-reperfusion induced rat kidney damage. Iran J Basic Med Sci 2014; 17: 986-992.

44. Maurya BK, Trigun SK. Fisetin modulates antioxidant enzymes and Inflammatory factors to inhibit Aflatoxin-B1-induced hepatocellular carcinoma in rats. Oxidat Med Cell Longev 2016; http://dx.doi. org/10.1155/2016/1972793.

45. Kumar S, Pandey AK. Phenolic content, reducing power and membrane protective activities of Solanum xanthocarpum root extracts. Vegetos 2013; 26: 301-307.

46. Winterbourn CC. Reconciling the chemistry and biology of reactive oxygen species. Nat Chem Biol 2008; 4: 278-286

47. Ben-Yoseph O, Ross B. Oxidation therapy: the use of a reactive oxygen species-generating enzyme system for tumor treatment. Brit J Cancer. 1994; 70: 1131 1135.

48. Talebi N, Nematbakhsh M, Monajemi R, Mazaheri S, Talebi A, Vafapour M. The protective effect of $\mathrm{V}$-aminobutyric acid on kidney injury induced by renal ischemia reperfusion in ovariectomized estradiol-treated rats. Int. J. Prev. Med. 2016; 7:6

49. Bonventre JV, Weinberg JM. Recent advances in the pathophysiology of ischemic acute renal failure. J. Am. Soc. Nephrol. 2003; 14: 2199-2210 